\title{
Morfodinâmica e a estabilidade da praia de Piratininga, Niterói (RJ)
}

\author{
André Luiz Carvalho da Silva ${ }^{1}$, Maria Augusta Martins da Silva ${ }^{2}$ \& Carla Luiza dos Santos ${ }^{3}$
}

\begin{abstract}
Resumo A praia de Piratininga, uma das mais populares de Niterói, vem apresentando problemas relativos à destruição do calçadão devido as fortes ondas de tempestade ao longo dos seus $2,5 \mathrm{~km}$ de comprimento. Buscando dar subsídios para o gerenciamento do problema e para o melhor entendimento da dinâmica sazonal, 30 perfis topográficos e 24 amostras foram coletados durante 5 anos, e os resultados foram comparados aos das décadas de 70 e 90. O atual regime de ondas consiste de ondas moderadas a fracas de sudeste e ondas de tempestade de sudoeste e de sul. Este padrão gera uma maior variabilidade do perfil de praia no setor oeste. Do mesmo modo, as areias são mais pobremente selecionadas neste setor. Os perfis de praia relativos às últimas três décadas não mostram mudanças significativas nesse período de observação. Assim, conclui-se que a praia tem estado em equilíbrio com o regime de ondas, pelo menos durante os últimos 30 anos. Isto indica que, ou as obras de engenharia deveriam ser reforçadas ou preferencialmente removidas para que o perfil original da restinga se restabeleça.
\end{abstract}

Palavras-chaves: Piratininga, dinâmica de praia, morfologia, sedimentologia, erosão.

\begin{abstract}
Morphodynamic and the stability of the Piratininga beach, Niterói (RJ), Brazil. The Piratininga beach, some 2,5 km long and one of the most popular in Niterói, has undergone major destruction of its sidewalks and concrete wall because of stormy waves. Thirty topographic profiles and twenty four samples were collected over five years to help resolve this problem and were compared with data collected in the 1970's and 1990 's. The present wave regime is as follows: today normal moderate to weak waves come from the southeast and stormy waves come from the southwest and south. This produces the greatest variability in the beach profile at its west end. Similarly, the sands are relatively poor sorted at the west end of the beach. Comparison with profiles from the 70's and 90's shows no significant change over the last 30 years. Thus, the conclusion is that the beach has been in equilibrium with its wave regime for at least 30 years. This tell us that the engineering structures should either be improved along the beach or preferentialy be removed and let the original profile return.
\end{abstract}

Keywords: Piratininga, beach dynamic, morphology, sedimentology, erosion.

INTRODUÇÃO O presente estudo objetiva contribuir para um maior entendimento do comportamento morfológico e sedimentar da praia de Piratininga (Niterói, RJ) (Fig. 1). A praia de Piratininga localiza-se na enseada de Itaipu, região oceânica de Niterói, onde se encontram várias praias importantes para a população do Rio de Janeiro e de Niterói, como Camboinhas e Itaipu. A praia tem cerca de $2,5 \mathrm{~km}$ de extensão na direção aproximada leste-oeste e é limitada por dois promontórios rochosos formados por gnaisse Pré-Cambriano. Ela se localiza em uma região densamente povoada, cuja ocupação se intensificou a partir da década de 70 , quando teve início a descaracterização da restinga com a remoção de dunas e da vegetação para a construção de casas e de pavimentação. Comumente, tais construções foram feitas em áreas submetidas aos processos de sobrelavagem das ondas durante as ressacas mais intensas, quando as ondas depositam areias além da faixa de praia, alcançando o ambiente de restinga (Fig. 2). A orla urbanizada de Piratininga vem apresentando problemas decorrentes da ação das ondas de ressacas, como a destruição do calçadão e do muro de concreto (Fig. 3).

O litoral de Piratininga é caracterizado por maré do tipo mista, semi-diurna, com amplitudes que não ultrapassam 1,40 m (DHN). Desta forma, as ondas constituem-se no principal agente responsável pela dinâmica e pela variabilidade morfológica deste litoral. As ondas incidentes são provenientes dos quadrantes $\mathrm{SE}, \mathrm{S}$ e SW. As ondas associadas às condições de tempo bom, geralmente provenientes de SE e de S, sofrem difração pelas ilhas do Pai, Mãe e Menina que limitam a enseada de Itaipu. Como resultado, a topografia do fundo entre as ilhas apresenta um comportamento diferenciado do fundo submarino atrás das ilhas (com relação à aproximação das ondas): nesses locais o fundo é mais raso, com características deposicionais, enquanto que entre as ilhas as profundidades são maiores (Fig. 4) (Salvador \& Silva 2002). A região submarina ao largo da praia estudada mostra um ambiente de face litorânea (shoreface) bastante íngreme (1:90) entre 3 e 16 me-

1 - Universidade Federal Fluminense, Programa de Pós-graduação em Geologia e Geofísica Marinha do Departamento de Geologia da UFF, Niteroi (RJ), Brasil. E-mail: andrelcsilva@igeo.uff.br

2 - Universidade Federal Fluminense, Departamento de Geologia da UFF, Niteroi (RJ), Brasil. E-mail: augusta@igeo.uff.br

3 - Universidade Federal Fluminense, Programa de Pós-graduação do Departamento de Geologia da UFF, Niteroi (RJ), Brasil. 


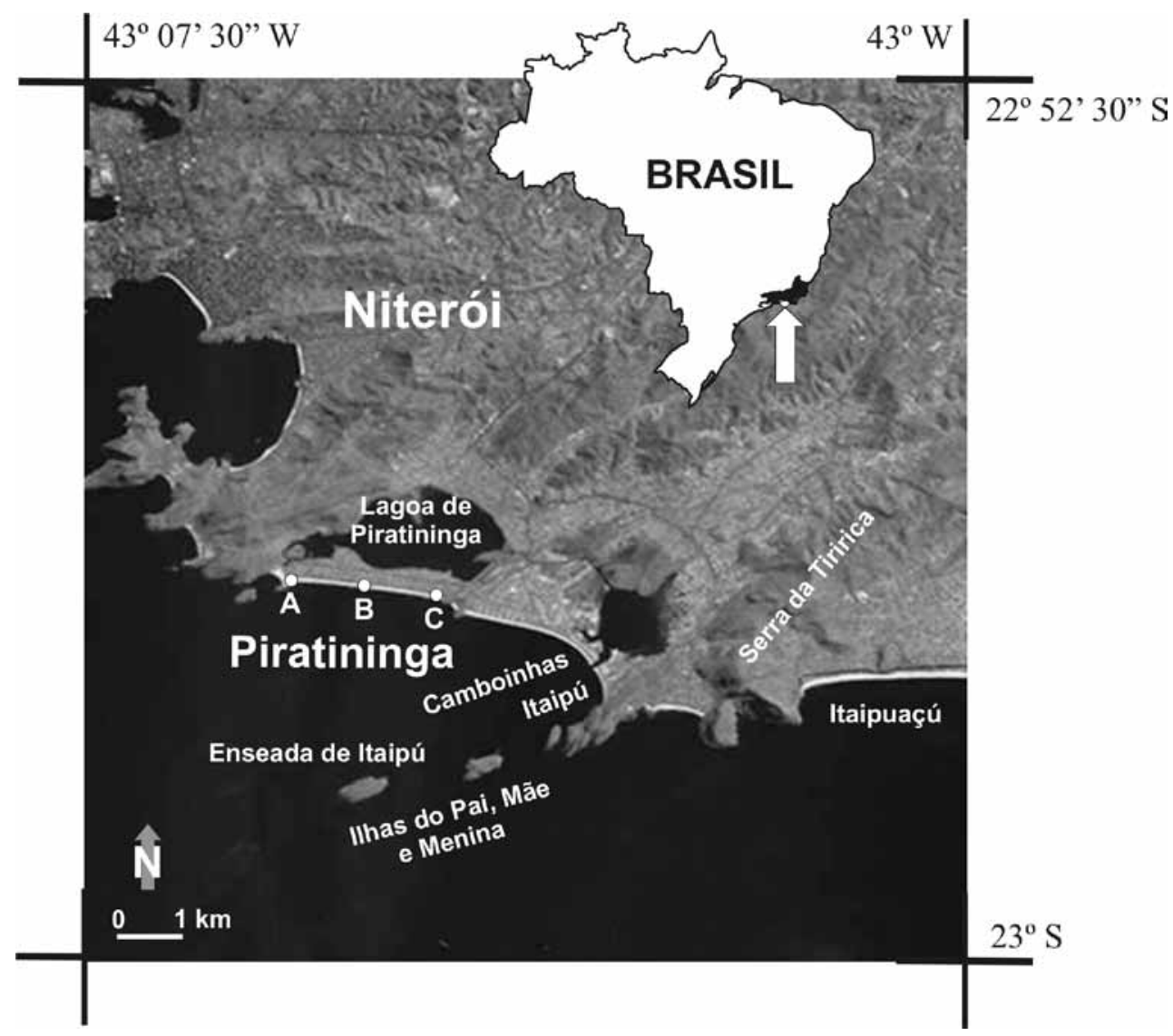

Figura 1 - Localização da área de estudo e dos locais de monitoramento na praia de Piratininga. Imagem Landsat (www.cdbrasil.cnpm.embrapa.br).
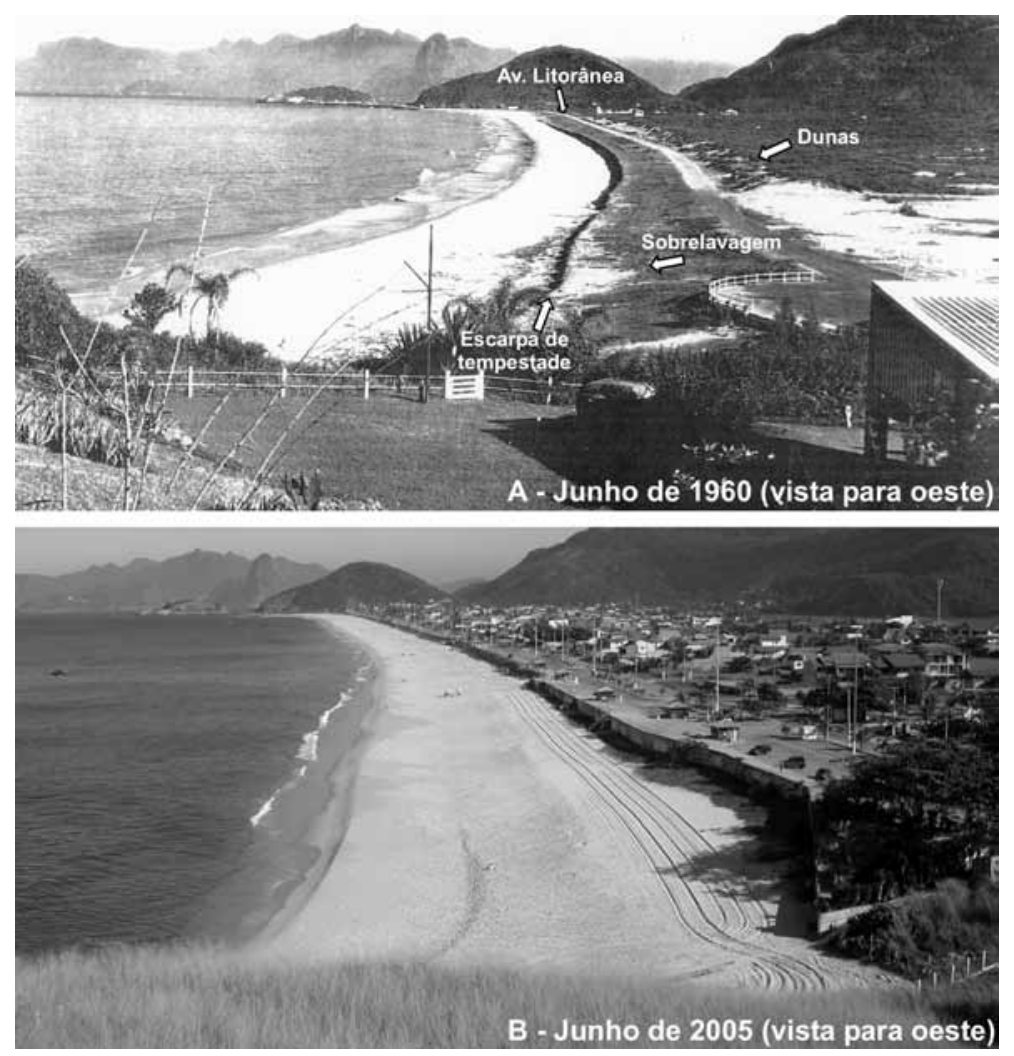

Figura 2 A e B - Praia de Piratininga em 1960 (foto: Baraúna) e 2005. Na fotografia da praia em 1960 a seta indica depósitos de areia por processos de sobrelavagem das ondas de ressacas. 

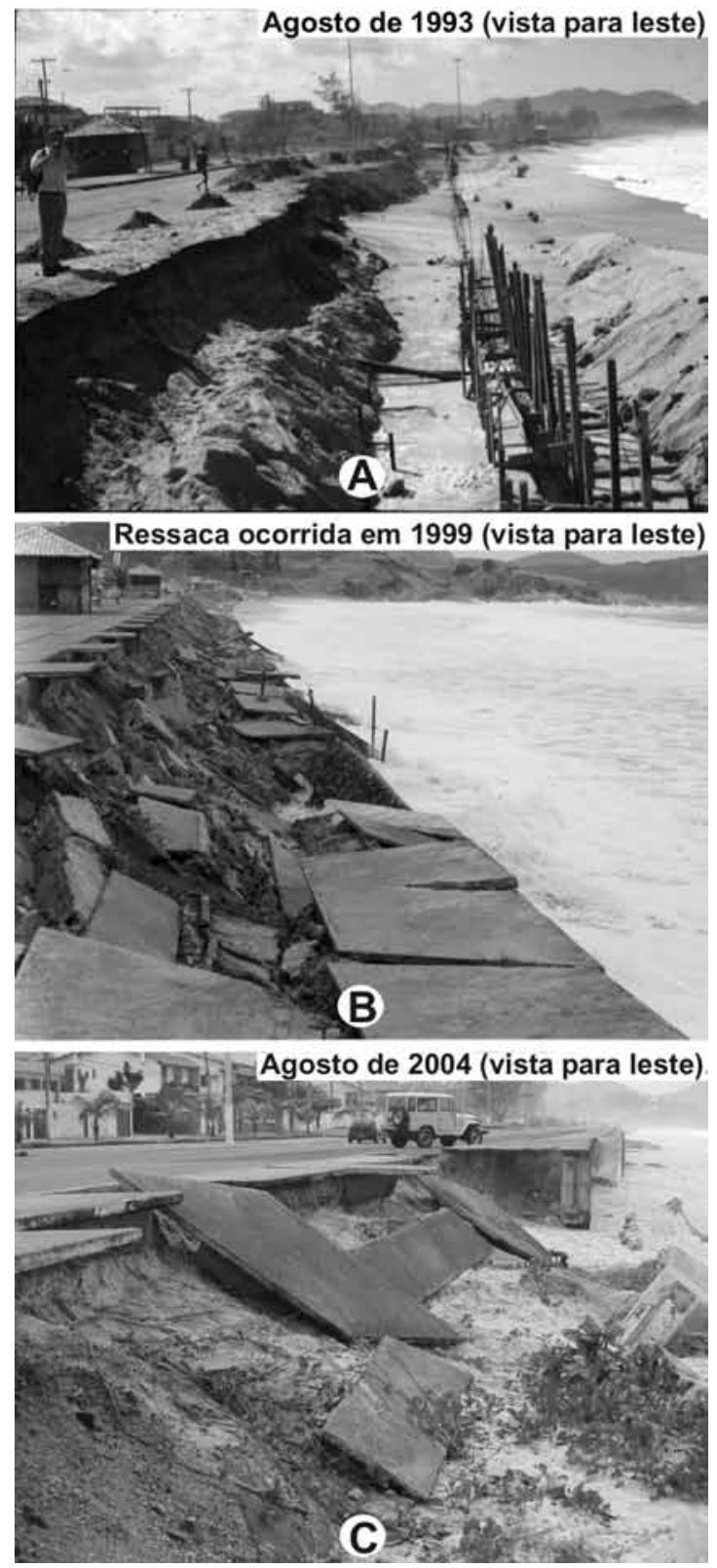

Figura 3 A, B e C - Calçadão na praia de Piratininga. (A) Fase de construção e a ação das ondas de tempestade junto à base do calçadão em agosto de 1993. (B) Calçadão sendo destruido durante uma ressaca ocorrida em 1999. (C) Calçadão parcialmente destruído em 9 de agosto de 2004.

tros de lâmina d'água, correspondendo a face litorânea superior; a partir daí o fundo mostra um gradiente mais suave (1:200) e passa a sofrer influência maior das ilhas, como descrito acima (Fig. 4) (Salvador \& Silva 2002). As ondas de tempestade, provenientes de $\mathrm{S}$ e principalmente as de SW, convergem diretamente sobre o arco praial, afetando principalmente o setor oeste mais exposto da praia (Bastos \& Silva 1995, Santos 2001, Santos et al. 2004, Silva 2006, Silva et al. 2006). Portanto, a praia apresenta uma dinâmica diferenciada ao longo do arco praial: o setor oeste é apontado como o mais

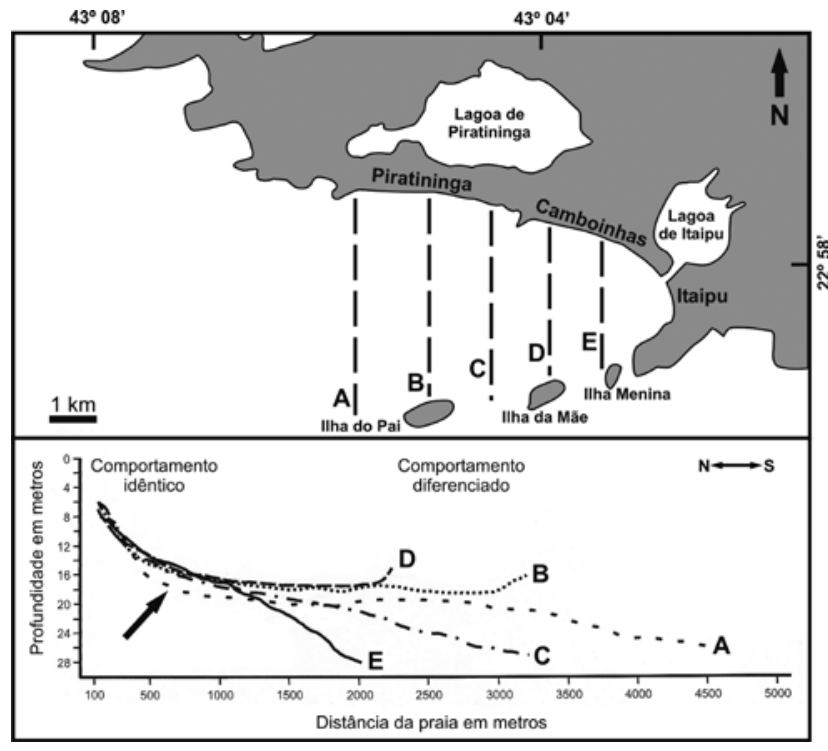

Figura 4 - A e B-Perfis batimétricos da enseada de Itaipu, orientados norte-sul. O perfil A apresentase com declividade mais acentuada (área indicada com a seta), em relação aos demais perfis (Salvador \& Silva, 2002 - menos a seta).

dinâmico, o de maior instabilidade e maior vulnerabilidade à atuação das ondas de tempestade (Bastos \& Silva 1995, Santos 2001, Santos et al. 2004). Observa-se que há um estreitamento da faixa arenosa na extremidade leste e o progressivo alargamento em direção a oeste em função do transporte de areias pelas correntes de deriva litorânea formadas pelas ondas predominantes de SE (Santos 2001, Santos et al. 2004, Silva 2006, Silva et al. 2006). A areia da praia de Piratininga é de tamanho médio, apresentando fragmentos de conchas de vários tamanhos (Muehe 1975, Santos 2001, Silva 2006); o grau de arredondamento varia entre sub angular e sub arredondado para a fração predominante $(0,250 \mathrm{~mm})$ (Mendes inédito).

Os estudos anteriormente realizados nesta praia pelos diversos autores (Muehe 1975, Bastos \& Silva 1995, Santos 2001, Santos et al. 2004) contribuíram de forma significativa para a aquisição de conhecimentos a cerca da dinâmica da praia como também apontam para os problemas existentes. Santos (2001) com base em registros de jornais sobre as ressacas, ao longo do último século, aponta os danos causados por estas na praia de Piratininga como a destruição da pavimentação da avenida Almirante Tamandaré em 1977, e a destruição do calçadão em 1988 e 1999. Souza et al. (2005) ressaltam a existência de vários indicadores de erosão em Piratininga, resultantes de fenômenos tanto naturais como de natureza antrópica, tais como: pós-praia muito estreito ou inexistente, destruição de estruturas artificiais como o calçadão. Muehe (1975) deu início a um projeto pioneiro de reconhecimento da morfologia das praias do litoral do Rio de Janeiro, entre Niterói e Cabo Frio, no qual o perfil topográfico do meio do arco de praia era obtido, como em Piratininga (na 


\section{Praia de Piratininga (antiga Mar Azul)}

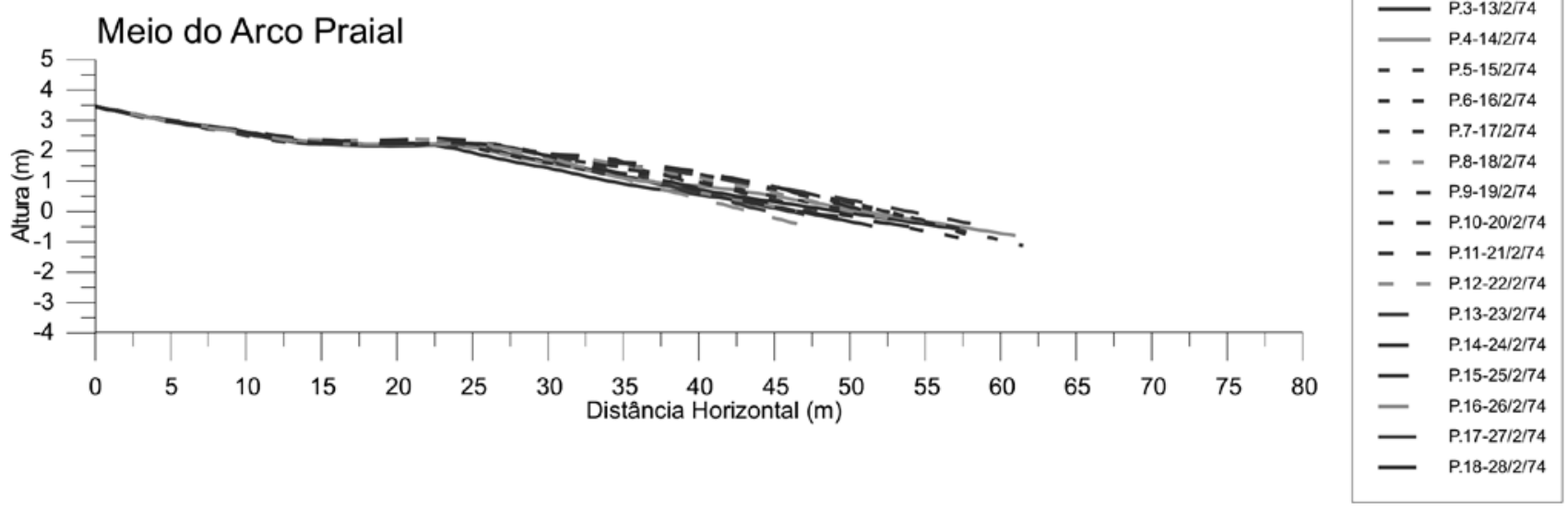

Figura 5 - Perfis topográficos mostrando as variações ocorridas no meio do arco praial de Piratininga no verão de 1974 (Muehe, 1975). Modificado por Santos \& Silva (inédito).

época chamada de Mar Azul) (Fig. 5). Projetos desta natureza permitem a criação de um banco de dados e a comparação com novos dados levantados com a mesma metodologia possibilita a caracterização da tendência de uma praia quanto à erosão ou estabilidade. Este é o objetivo deste trabalho, integrar novos dados coletados sistematicamente ao longo de 5 anos com os existentes para a década de 70 . A reunião de todos esses dados permitiu o entendimento do comportamento morfosedimentar da praia de Piratininga nas últimas três décadas e desse modo verificar a tendência erosiva ou de estabilidade face às condições oceanográficas e geológicas. Finalmente, este trabalho contribui para uma discussão sobre as causas que levam a destruição dos projetos urbanísticos para esta orla.

METODOLOGIA Ao longo de 5 anos contínuos, sempre nos verões e invernos, foram coletados dados topográficos e amostras de areia em 3 locais do arco praial (Fig. 1). Para os perfis topográficos de praia utilizou-se o método das balizas proposto por Emery (1961) que consiste na realização de perfis perpendiculares à linha de praia, começando no limite interno da praia, indo até o alcance médio das ondas, alinhando-se 3 balizas perpendicularmente a linha d'água e obtendo-se a diferença vertical entre dois pontos tendo como referência a projeção da linha do horizonte nas balizas. A coleta de dados foi sempre realizada nas mesmas condições de maré baixa de quadratura. Concomitantemente, 24 amostras de sedimentos superficiais foram coletadas e analisadas para a classificação da granulometria. Os locais de coleta das amostras de sedimentos superficiais correspondem aos trechos onde foram realizados os perfis de praia, sendo que, em cada uma dessas áreas, a amostragem foi feita na área do pós-praia (região de supramaré - parte emersa da praia) e frente de praia (região de intermaré - parte da praia sujeita ao alcance diário das ondas). A coleta da amostra foi realizada nos primeiros centímetros de sedimentos superficiais, abrangendo uma área representativa do perfil estudado.

$\mathrm{Na}$ análise granulométrica das amostras, realizada no laboratório de sedimentologia do Departamento de Geologia do Instituto de Geociências da UFF, utilizou-se um conjunto de peneiras com abertura em milímetros de 4.00, 2.83, 2.00, 1.00, 0.500, 0.250, 0.125 e 0.062 . Os resultados das análises granulométricas foram processados no Microsoft Excel, que possibilitou a confecção dos histogramas e a classificação dos sedimentos, o que foi feito baseando-se na classificação proposta por Wentworth (1922) citado por Peittijohn (1975).

Por ocasião dos levantamentos foram observadas algumas das características das condições de mar, tais como: altura da onda na arrebentação, tipo de arrebentação, direção de chegada das ondas e período médio das ondas (sempre estimada por 2 ou 3 pessoas).

Os dados referentes aos perfis topográficos foram processados no software Grapher. A geração de perfis de praia individuais permite a caracterização morfológica da praia por ocasião da coleta de dados e a sobreposição dos mesmos permite a observação das variações morfológicas da praia ao longo do tempo de monitoramento. Os resultados podem ser comparados aos perfis pretéritos permitindo com isso uma compreensão das variações ao longo de um intervalo de tempo maior.

\section{RESULTADOS E DISCUSSÃO}

Caracterização das condições de mar em Piratininga $\mathrm{O}$ mar na região pode ser caracterizado pela incidência de ondas provenientes de S (Fig. 6A) e de SE associadas às condições de tempo bom o ano inteiro (Tab. 1). A menor observância nos monitoramentos da incidência de ondas de SE chegando junto à praia, provavelmente se deve à influência dos processos de difração e refração, condicionados pela existência das ilhas do Pai, Mãe e Menina (Fig. 1). Estas ondas, durante as observações de campo, apresentaram altura média 


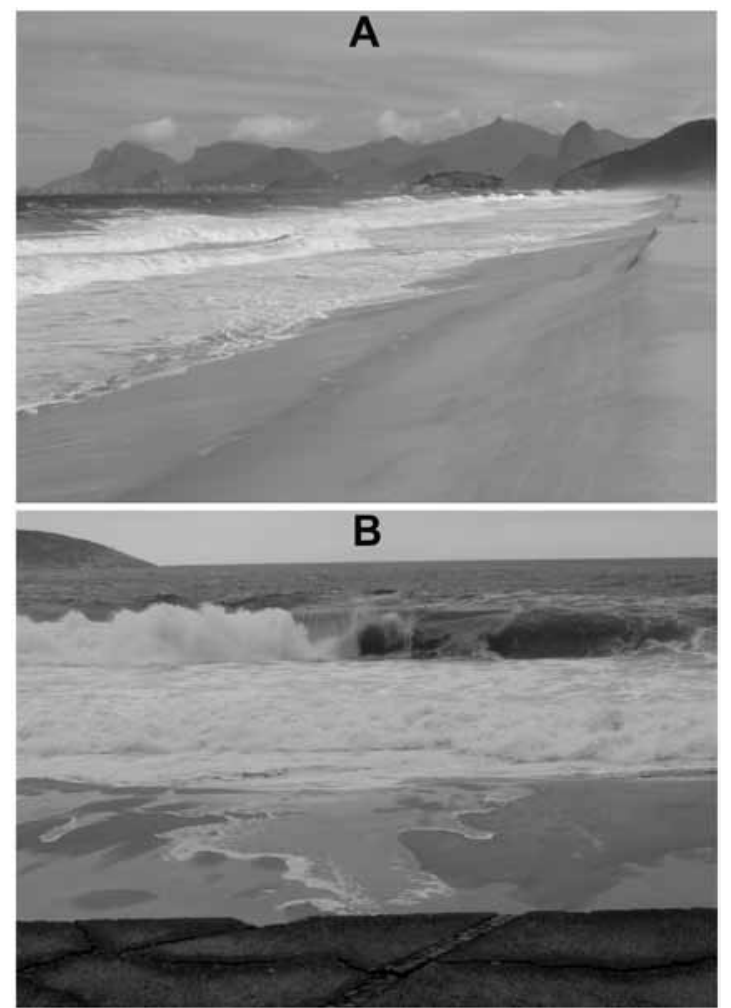

Figura 6 A e B - (A) Incidência de ondas de sul com arrebentação do tipo progressiva (situação de tempo bom em 09 de agosto de 2004); (B) Incidência de ondas provenientes de sul com arrebentação do tipo mergulhante (ressaca ocorrida em 19 de julho de 2005).

entre 0,25 e 0,65 metro, aproximadamente, chegando a atingir uma média superior a $1 \mathrm{~m}$ no inverno de 2004; apresentaram período variando entre 7.5 (verão-2006) e 13.2 segundos (inverno-2005).

As ondas de alta energia associadas a tempestades (Fig. 6B), são provenientes de S e, principalmente, de SW. A altura observada variou entre 0,90 e 1,50 metros, chegando a ultrapassar 2 metros de altura. Apresentaram período médio superior a 10 segundos.

A forma de arrebentação das ondas varia, predominando o tipo mergulhante (plunging), seguido por progressiva (spilling) e colapsante (colapsing) em menor proporção. A arrebentação das ondas propicia a formação de uma estreita zona de surfe, que se apresenta mais desenvolvida na porção oeste da praia (Fig. 6B).

Nesta praia predominam correntes de deriva litorânea com direção oeste, em função da incidência oblíqua de ondas provenientes de sudeste (Bastos \& Silva 1995, Santos et al. 2004). Porém, correntes de deriva litorânea com direção leste foram também observadas. No inverno de 2005, por exemplo, verificou-se a existência de correntes de deriva litorânea em direção a leste no meio do arco praial e no setor leste da praia; ao mesmo tempo observou-se uma forte corrente com direção oeste no setor oeste da praia. Tal processo decorre da incidência de ondas provenientes de mais de
Tabela 1 - Dados relativos às condições de mar observadas na praia de Piratininga por ocasião dos trabalhos de campo: direção da frente de ondas e forma de arrebentação (M, Mergulhante; $P$, progressiva; $C$, Colapsante), estado de mar, altura da arrebentação $(H) e$ período (T) das ondas junto à praia.

\begin{tabular}{|c|c|c|c|c|}
\hline \multicolumn{5}{|c|}{ Praia de Piratininga } \\
\hline & & Perfil A & Perfil B & Perfil C \\
\hline \multirow{5}{*}{ 总 } & Direção & SW & SW & SW \\
\hline & Arrebentação & $\mathrm{M}, \mathrm{P}$ & $\mathrm{M}, \mathrm{P}$ & $\mathrm{P}, \mathrm{M}$ \\
\hline & Mar & agitado & agitado & agitado \\
\hline & Altura $(\mathrm{H})$ & $1,48 \mathrm{~m}$ & $1,18 \mathrm{~m}$ & $0,90 \mathrm{~m}$ \\
\hline & Período (T) & $11.6 \mathrm{~s}$ & $11.0 \mathrm{~s}$ & $13.0 \mathrm{~s}$ \\
\hline \multirow{5}{*}{ 㞼 } & Direção & $\mathrm{S}$ & $\mathrm{S}$ & $\mathrm{S}$ \\
\hline & Arrebentação & $\mathrm{M}, \mathrm{P}$ & $\mathrm{M}, \mathrm{P}$ & $\mathrm{P}, \mathrm{M}$ \\
\hline & Mar & calmo & calmo & calmo \\
\hline & Altura $(\mathrm{H})$ & $0,61 \mathrm{~m}$ & $0,43 \mathrm{~m}$ & $0,57 \mathrm{~m}$ \\
\hline & Período $(\mathrm{T})$ & $10.7 \mathrm{~s}$ & $10.7 \mathrm{~s}$ & $10.1 \mathrm{~s}$ \\
\hline \multirow{5}{*}{ 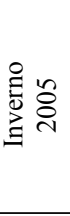 } & Direção & $\mathrm{S}, \mathrm{SE}$ & $\mathrm{S}, \mathrm{SE}$ & S, SW \\
\hline & Arrebentação & $\mathrm{M}$ & $\mathrm{M}$ & $\mathrm{M}$ \\
\hline & Mar & calmo & calmo & calmo \\
\hline & Altura $(\mathrm{H})$ & $0,67 \mathrm{~m}$ & $0,46 \mathrm{~m}$ & $0,53 \mathrm{~m}$ \\
\hline & Período (T) & $11.7 \mathrm{~s}$ & $12.7 \mathrm{~s}$ & $13.2 \mathrm{~s}$ \\
\hline \multirow{5}{*}{ 㞼 } & Direção & $\mathrm{S}$ & $\mathrm{S}$ & $\mathrm{S}, \mathrm{SW}$ \\
\hline & Arrebentação & $\mathrm{M}, \mathrm{P}, \mathrm{C}$ & $\mathrm{M}, \mathrm{P}, \mathrm{C}$ & $\mathrm{C}, \mathrm{P}$ \\
\hline & Mar & calmo & calmo & calmo \\
\hline & Altura $(\mathrm{H})$ & $0,42 \mathrm{~m}$ & $0,34 \mathrm{~m}$ & $0,24 \mathrm{~m}$ \\
\hline & Período (T) & $09.8 \mathrm{~s}$ & $11.3 \mathrm{~s}$ & $07.5 \mathrm{~s}$ \\
\hline
\end{tabular}

uma direção ao mesmo tempo (S, SE e SW), como o observado no inverno de 2005 (Tab. 1).

Caracterização da granulometria das areias da praia de Piratininga A análise granulométrica das 24 amostras superficiais permitiu confirmar a predominância da fração arenosa de $0,25 \mathrm{~mm}$, correspondendo a areia média, ao longo dos cerca de 2,5 quilômetros de praia. Tal resultado corrobora dados anteriores (Muehe 1975).

Os histogramas mostram um aumento percentual da fração 0,500 mm em direção a extremidade oeste, (Fig. 7). O grau de selecionamento apresenta um padrão de ligeira melhora em direção a leste. Estudo realizado por Santos (2001) na praia de Camboinhas, localizada à leste da praia de Piratininga (Fig. 1), constatou o predomínio de areia média ao longo da praia, com ligeiro aumento dos grãos de areia junto ao extremo oeste. Constatou-se ainda, um grau de selecionamento mais alto no meio do arco e no extremo leste. Trata-se de um comportamento semelhante ao apresentado pela praia de Piratininga.

Dinâmica sazonal da praia de Piratininga Entre os anos de 2001 e 2006, o arco praial de Piratininga apresentou na sua totalidade uma dinâmica mais expressiva e maior variabilidade morfológica nos extremos leste e oeste, sendo ainda mais intensa no setor 


\section{Extremo oeste - PA}
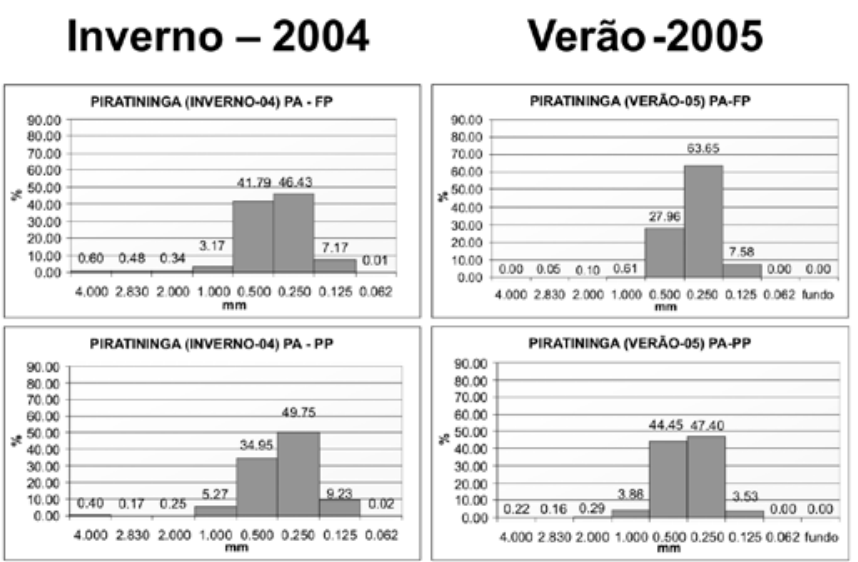

\section{Inverno-2005}

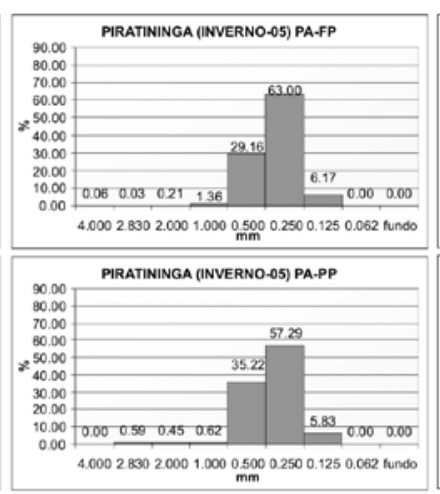

Verão-2006

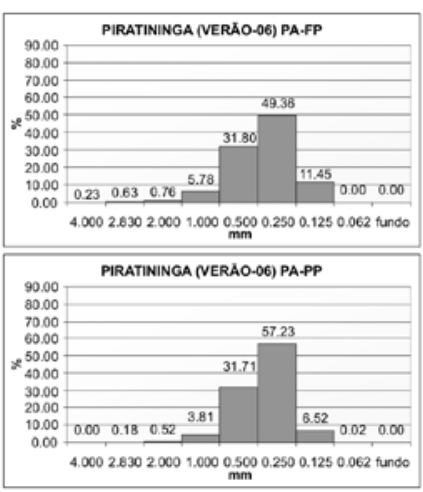

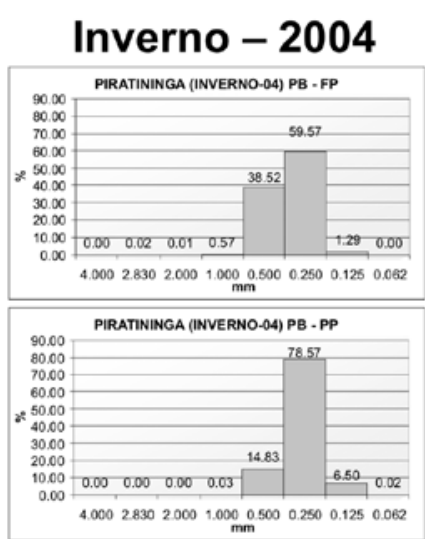
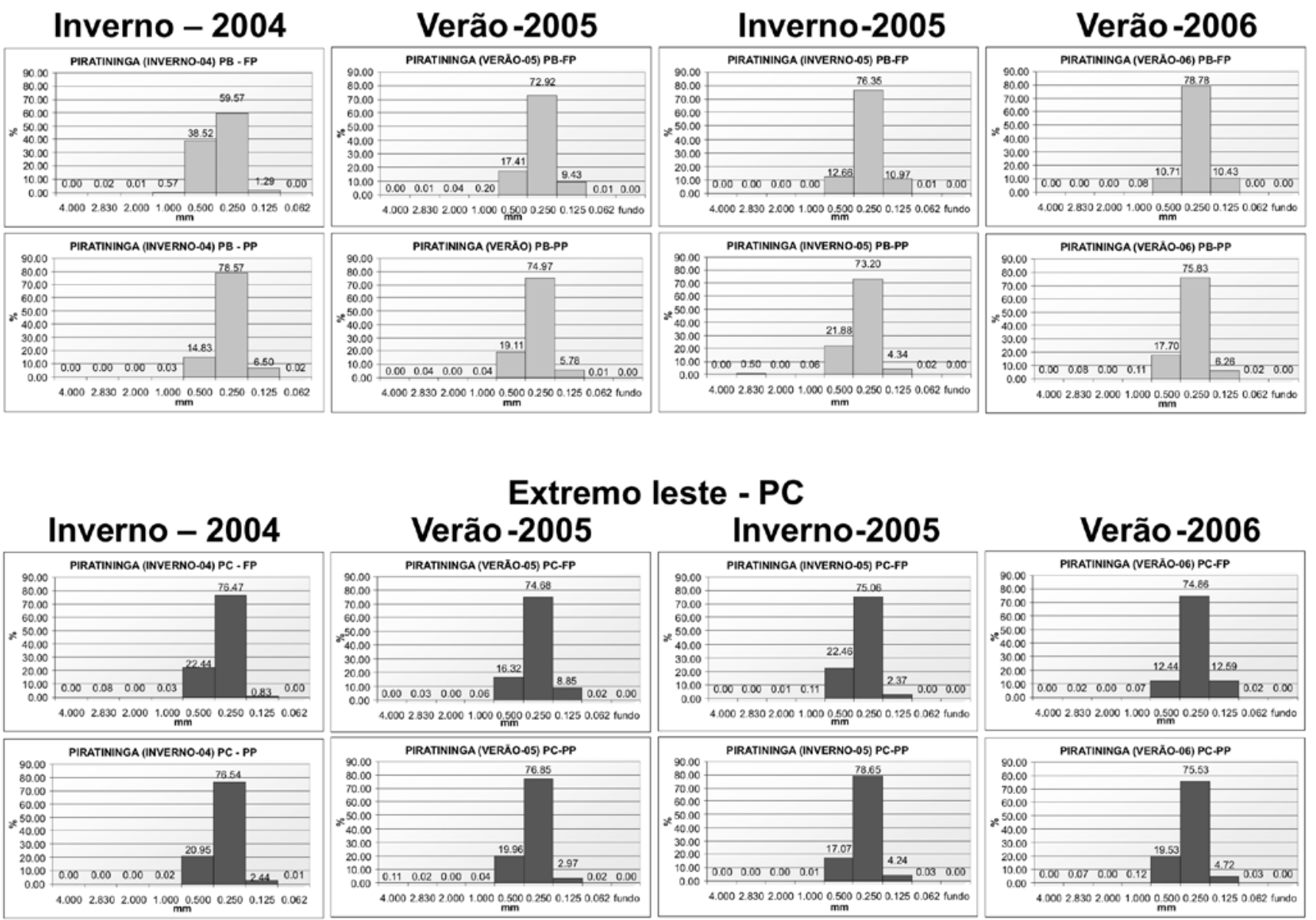

Figura 7 - Histogramas com os resultados das análises granulométricas das amostras de superfície coletadas na praia de Piratininga: área dos perfis $A, B$ e C, na frente de praia (FP) e no pós-praia (PP).

oeste (perfil A) (Fig. 8).

O setor oeste (perfil A) da praia de Piratininga apresentou uma largura máxima de 100,5 m (verão de 2005) e uma largura mínima de $22,5 \mathrm{~m}$ (inverno de 2003); o meio do arco praial (perfil B) apresentou uma largura máxima de $74,5 \mathrm{~m}$ (verão de 2006) e uma largura mínima de $38 \mathrm{~m}$ (inverno de 2003), sendo este o trecho com menor variabilidade na largura do perfil; no extremo leste (perfil C), os dados existentes mostram uma largura máxima de 72 m (verão de 2001) e uma largura mínima de $42 \mathrm{~m}$ (inverno de 2004); neste trecho, os perfis coletados são relativamente parecidos, com poucas diferenças na largura da praia (Fig. 8 e Tab. 2). Perfis topográficos coletados apresentam um 


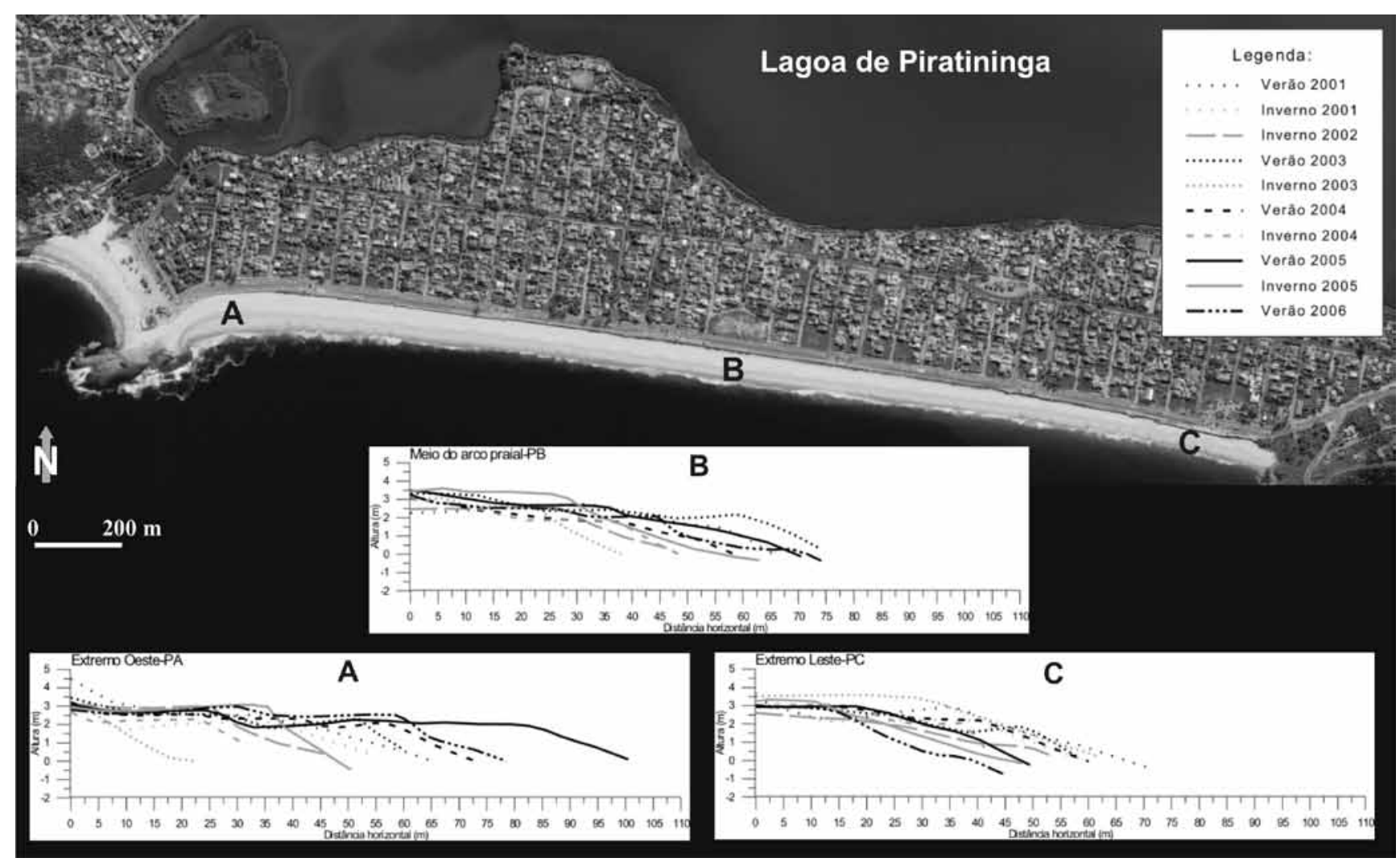

Figura 8 - Perfis topográficos de praia realizados em Piratininga entre o verão de 2001 e 2006. Imagem do satélite IKONOS (do ano de 2003).

Tabela 2 - Dados relativos às variações na morfologia da praia de Piratininga entre verão e inverno (2001 a 2006).

\begin{tabular}{|c|c|c|c|c|c|c|c|c|}
\hline \multicolumn{9}{|c|}{ Praia de Piratininga } \\
\hline & & & $\begin{array}{l}\text { Pós-praia } \\
\text { (PP) }\end{array}$ & & Frente & aia (FP) & $\begin{array}{c}\text { Largura da } \\
\text { praia }\end{array}$ & $\begin{array}{c}\text { Diferença }(\mathrm{m}) \\
\text { entre }\end{array}$ \\
\hline & $\begin{array}{l}\text { Estação e } \\
\text { ano do perfil }\end{array}$ & $\begin{array}{l}\text { Largura } \\
\text { (m) }\end{array}$ & $\begin{array}{l}\text { Altura } \\
(\mathrm{m})\end{array}$ & $\begin{array}{c}\mathrm{N}^{\circ} \mathrm{de} \\
\text { bermas }\end{array}$ & $\begin{array}{l}\text { Largura } \\
(\mathrm{m})\end{array}$ & Inclina-ção & $\begin{array}{l}\mathrm{PP}+\mathrm{FP} \\
(\mathrm{m})\end{array}$ & $\begin{array}{c}\text { verão e } \\
\text { inverno } \pm\end{array}$ \\
\hline \multirow{10}{*}{ 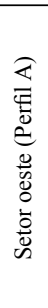 } & Verão - 2001 & 33 & 4,5 & 1 & 33 & $19^{\circ}$ & 66 & \\
\hline & Inverno -2001 & 37 & 2,9 & 1 & 17,5 & $19^{\circ}$ & 54,5 & $-11,5$ \\
\hline & Inverno -2002 & 25,5 & 3,2 & 1 & 21 & $20^{\circ}$ & 46,5 & $\#$ \\
\hline & Verão - 2003 & 52 & 3,4 & 3 & 7,5 & $32^{\circ}$ & 59,5 & +13 \\
\hline & Inverno -2003 & 4 & 2,8 & 0 & 18,5 & $20^{\circ}$ & 22,5 & -37 \\
\hline & Verão - 2004 & 57 & 3,2 & 3 & 16 & $20^{\circ}$ & 73 & $+50,5$ \\
\hline & Inverno -2004 & 22,5 & 2,6 & 1 & 9 & $23^{\circ}$ & 31,5 & $-41,5$ \\
\hline & Verão - 2005 & 82,5 & 3,0 & 3 & 18 & $17^{\circ}$ & 100,5 & +69 \\
\hline & Inverno -2005 & 35,5 & 3,0 & 1 & 15 & $45^{\circ}$ & 50,5 & -50 \\
\hline & Verão - 2006 & 58 & 2,8 & 2 & 20,5 & $20^{\circ}$ & 78,5 & +28 \\
\hline \multirow{10}{*}{ 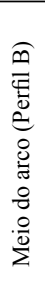 } & Verão-2001 & 56 & 2,3 & 1 & 10 & $28^{\circ}$ & 66 & \\
\hline & Inverno - 2001 & 26 & 2,5 & 1 & 21,5 & $18^{\circ}$ & 47,5 & $-18,5$ \\
\hline & Inverno -2002 & * & $*$ & * & $*$ & $*$ & $*$ & * \\
\hline & Verão - 2003 & 59 & 3,3 & 3 & 14,5 & $16^{\circ}$ & 73,5 & \\
\hline & Inverno -2003 & 23,5 & 3,0 & 2 & 14,5 & $26^{\circ}$ & 38 & $-35,5$ \\
\hline & Verão - 2004 & 50 & 3,0 & 1 & 11,5 & $18^{\circ}$ & 61,5 & $+23,5$ \\
\hline & Inverno -2004 & 37,5 & 3,0 & 1 & 12 & $23^{\circ}$ & 49,5 & -12 \\
\hline & Verão - 2005 & 36 & 3,5 & 1 & 34,5 & $15^{\circ}$ & 70,5 & +21 \\
\hline & Inverno -2005 & 30 & 3,4 & 1 & 33 & $18^{\circ}$ & 63 & $-7,5$ \\
\hline & Verão - 2006 & 68 & 3,3 & 2 & 6,5 & $21^{\circ}$ & 74,5 & $+11,5$ \\
\hline \multirow{10}{*}{ 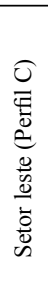 } & Verão -2001 & 37 & 3,5 & 1 & 35 & $18^{\circ}$ & 72 & \\
\hline & Inverno -2001 & 40 & 3,6 & 1 & 20 & $19^{\circ}$ & 60 & -12 \\
\hline & Inverno -2002 & 20 & 2,6 & 1 & 33 & $17^{\circ}$ & 53 & \# \\
\hline & Verão - 2003 & 47,5 & 3,0 & 2 & 10,5 & $21^{\circ}$ & 58 & +5 \\
\hline & Inverno -2003 & 28,5 & 3,5 & 1 & 33 & $18^{\circ}$ & 61,5 & $+3,5$ \\
\hline & Verão -2004 & 41 & 3,0 & 2 & 19 & $19^{\circ}$ & 60 & $-1,5$ \\
\hline & Inverno -2004 & 37 & 3,0 & 2 & 5 & $40^{\circ}$ & 42 & -18 \\
\hline & Verão -2005 & 19 & 3,0 & 1 & 30,5 & $20^{\circ}$ & 49.5 & $+7,5$ \\
\hline & Inverno -2005 & 11 & 3,3 & 1 & 37 & $18^{\circ}$ & 48 & $-1,5$ \\
\hline & Verão - 2006 & 15 & 3,0 & 1 & 30 & $19^{\circ}$ & 45 & -3 \\
\hline
\end{tabular}

\pm A diferença é calculada em relação à largura da praia verificada no monitoramento anterior, sempre entre verão e inverno.

* Perfil topográfico não realizado.

\# O monitoramento referente ao verão de 2002 não foi realizado, o que impossibilitou a comparação da largura da praia entre inverno e verão de 2002. 
comportamento idêntico para os perfis de verão e de inverno: todos os perfis coletados no verão são mais largos, sobretudo no setor oeste, evidenciando um comportamento clássico. A praia assim reflete um período caracterizado pela ação predominante de ondas construtivas. Estas ondas provenientes de sudeste incidem obliquamente junto à praia formando correntes de deriva litorânea para oeste, que ocasionam um transporte lateral de sedimentos que se acumulam junto ao setor oeste, onde são contidos pelo costão. Perfis realizados no inverno são mais estreitos, com o estreitamento das extremidades da praia no inverno, principalmente no perfil $\mathrm{A}$, em resposta à ação de ondas de tempestade de sul e de sudoeste (Fig. 8 e Tab. 2).

Apresentando-se sempre mais estreito no inverno, o setor oeste da praia reflete a maior vulnerabilidade deste trecho à ação das ondas de ressacas. As diferenças na variação da largura da praia neste trecho, entre verão e inverno, parecem ter aumentado nos últimos anos. Nos monitoramentos realizados entre verão e inverno de 2001 observou-se um estreitamento de cerca de $11 \mathrm{~m}$, em 2003 o estreitamento foi de $37 \mathrm{~m}$ aproximadamente, em 2004 da ordem de $40 \mathrm{~m}$ e em 2005 a diferença aumentou para $50 \mathrm{~m}$. Trata-se de um aumento significativo na variação da largura da praia. Perfis topográficos de praia realizados em 1993 (Bastos \& Silva 1995), foram levantados durante e entre a passagem de frentes frias. Tais perfis indicam que a praia apresentava larguras variando entre 17 e 55 metros e apontam também uma dinâmica diferenciada ao longo da praia, onde os perfis coletados no extremo oeste mostram maior variabilidade.

Os perfis topográficos realizados em 1974
(Muehe 1975) no meio do arco praial de Piratininga, foram coletados diariamente ao longo de 18 dias no verão e, apresentam poucas variações, tanto na morfologia, quanto na largura que variou entre 47 e 62 metros (Fig. 5). A comparação dos perfis topográficos adquiridos neste estudo (Fig. 8), com os realizados no ano de 1974 (Muehe 1975) mostra que a largura da praia no meio do arco praial, no período de maior engordamento da mesma, tem sido praticamente a mesma, ao longo de três décadas de monitoramento, com uma variação que corresponde a dinâmica do próprio ambiente. Tal variação, não indica tendência de efetivo alargamento nem estreitamento, muito menos caracteriza um comportamento erosivo.

Para Bastos \& Silva (1995), a praia de Piratininga vem apresentando um processo erosivo, sobretudo na extremidade oeste. Souza et al. (2005), ressaltam a existência, na referida praia, de vários indicadores de erosão, tais como: pós-praia muito estreito ou inexistente, e, destruição de estruturas artificiais (como o calçadão). Como causas da erosão, atribui efeitos e processos tanto de ordem natural quanto antrópica. No entanto, os resultados aqui apresentados não corroboram a hipótese de que a referida praia esteja sofrendo erosão.

Perfis batimétricos obtidos por Salvador \& Silva (2002) na enseada de Itaipu, permite caracterizar a face litorânea da área de estudo (fig. 4) como bastante íngreme, com um gradiente da ordem de 1:90. O perfil A, junto a praia de Piratininga a oeste da enseada é o mais íngreme de todos no mesmo espaço, tendo sido explicado como o resultado do ataque das ondas de tempestade provenientes de sudoeste (Salvador \& Sil-

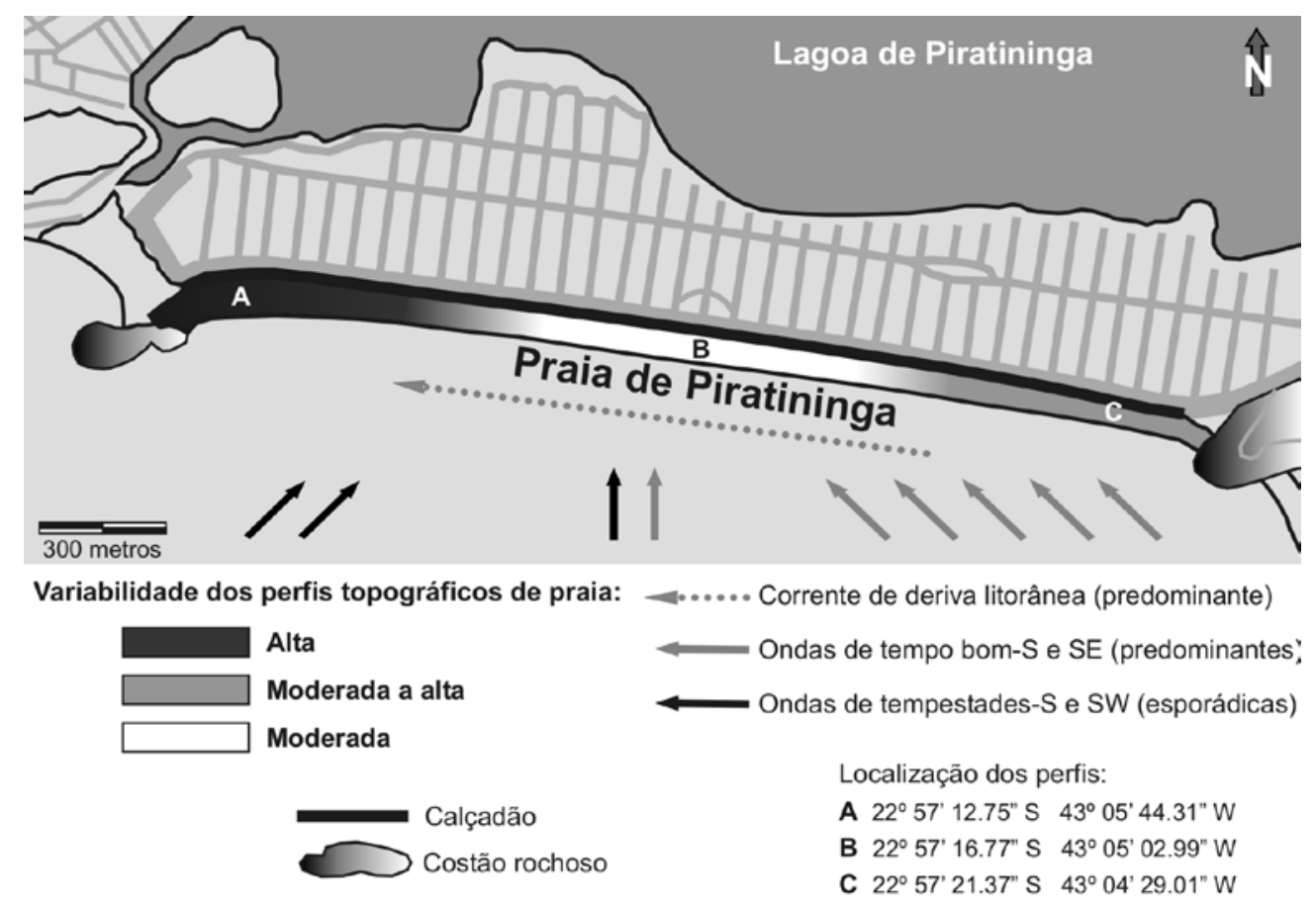

Figura 9 - Mapa de variabilidade morfológica da praia de Piratininga. 
va 2002). Sendo assim, apesar dos perfis topográficos de praia não apontarem para uma situação onde predominam processos de erosão, a elevada declividade do fundo submarino neste trecho (perfil A) pode estar indicando ser a face litorânea superior um local potencial de remoção de areias e, portanto erosão.

A sobreposição dos perfis topográficos de praia coletados ao longo do desenvolvimento desta pesquisa, entre 2001 e 2006, e a comparação com os dados da década de 1970 (Muehe 1975) e de 1990 (Bastos \& Silva 1995) permite constatar uma variabilidade morfológica diferenciada ao longo do arco praial de Piratininga, com elevada variabilidade dos perfis topográficos de praia no setor oeste, moderada no meio do arco praial e moderada a alta no setor leste (Fig. 9). A comparação dos perfis topográficos realizados num intervalo de tempo de 3 décadas não aponta para uma situação característica de erosão. Os perfis não expressam uma diminuição da largura da praia, o que caracterizaria o processo de erosão.

CONCLUSÕES A realização deste estudo possibilitou uma melhor compreensão da dinâmica da praia de Piratininga. A praia de Piratininga apresentou consideráveis variações morfológicas, em especial variações na largura, junto às extremidades leste e oeste de seu arco, sendo mais intensa no setor oeste. Dados existentes, os quais somados a estes cobrem um intervalo de tempo de 30 anos, corroboram esses resultados que são característicos da dinâmica do próprio ambiente de praia. Os perfis topográficos realizados no meio do arco praial no verão de 1974 apresentaram variação na largura entre 47 e $62 \mathrm{~m}$. Estes valores são, em média, pouco inferiores aos observados nos verões ao longo dos 5 anos de realização deste estudo, que variaram de $58 \mathrm{~m}$ a $74,5 \mathrm{~m}$. Desta forma, conclui-se que o comportamento da praia de Piratininga não pode ser caracterizado como erosivo. O setor oeste da praia, mais dinâmico, responde com grande redução principalmente na largura no inverno e alargando-se no verão rapidamente em resposta às alterações nas condições de mar. As diferenças na largura da praia entre verão e inverno neste trecho são expressivas: houve uma redução de $37 \mathrm{~m}$ do verão ao inverno de 2003 , seguido de um alargamento de $50 \mathrm{~m}$ no verão e um estreitamento de $41,5 \mathrm{~m}$ no inverno de 2004 , alargando-se novamente $69 \mathrm{~m}$ no verão e estreitando-se $50 \mathrm{~m}$ no inverno de 2005. Essa dinâmica acentuada neste trecho é condicionada pela incidência das ondas de tempestade de sudoeste e a interação das mesmas com o costão; pela prolongada ação das ondas construtivas de sudeste e conseqüente formação da corrente de deriva litorânea no sentido oeste. A variação na largura ao longo do arco de praia sugere a ação da corrente de deriva litorânea para oeste nos monitoramentos realizados no verão de 2004, 2005 e 2006. O papel preponderante das correntes de deriva litorânea no transporte longitudinal de sedimentos e o deslocamento transversal das areias da face de praia para a frente de praia, e vice-versa, é o principal mecanismo responsável pela mobilidade dos sedimentos ao longo da praia de Piratininga.

Os sedimentos superficiais da praia de Piratinin- ga apresentam grande uniformidade quanto ao tamanho e grau de selecionamento nos cerca de 2,5 quilômetros de arco praial: as areias predominantes são de fração $0,25 \mathrm{~mm}$ (areias médias) com um ligeiro aumento do grau de selecionamento para leste.

A construção em local impróprio de um calçadão e paredão de 4,5 metros de altura em ambiente de praia e de restinga (abrangendo a área de sobrelavagem das ondas de tempestade mais intensas) ocasiona um aumento na energia das ondas que incidem sobre a praia. A energia das ondas de tempestades, normalmente dissipada pela faixa de areias, incide diretamente no paredão aumentando a capacidade das ondas de mobilizar areias para o mar, causando diminuição na quantidade de areia estocada na praia e eventual destruição das construções urbanas. Essa redução de areia na praia, ao que tudo indica, vem sendo compensada pelo suprimento de areias da face litorânea. A declividade acentuada da face litorânea na área do perfil A indica que esta região submarina, ao largo da zona de arrebentação, é a que mais perde areia para a praia e, portanto, onde o processo erosivo pode estar ocorrendo.

Desta forma, conclui-se que a praia de Piratininga, no intervalo de tempo aqui considerado, não apresenta comportamento erosivo, mas se trata de uma praia com elevada dinâmica e que se estreita consideravelmente com as ondas de tempestades. Em função do rápido processo de urbanização que vem ocorrendo neste trecho do litoral, nem sempre se respeitando a dinâmica característica deste ambiente, como pode ser constatado com a construção de obras de engenharia dentro dos limites da praia e a conseqüente destruição das mesmas, considera-se preocupante a situação dessa região. Este quadro reforça a necessidade de se realizar estudos prévios antes de qualquer intervenção, sobretudo por se tratar de ambientes essencialmente dinâmicos.

Agradecimentos $\mathrm{O}$ presente estudo integra resultados obtidos ao longo de diversos projetos desenvolvidos junto ao Departamento de Geologia-UFF, que possibilitaram a elaboração de dissertações de mestrado, monografias e projetos voltados para o entendimento da dinâmica do litoral de Niterói/RJ. Agradecimentos a CAPES pela concessão das bolsas de mestrado e a FAPERJ (processo $n^{\circ}$ E-261151-353/01). Agradecimentos aos doutores Luis Somoza Losada (Instituto Geológico y Minero, Madrid, España) e Emmanuele Lodolo (Istituto Nazionale di Oceanografia e di Geofisica Sperimentale, Trieste, Italia) pelas considerações feitas a este trabalho durante a realização da campanha Antártica SCAN-2008. Ao Dr. Paul E. Potter (Departamento de Geologia da Universidade de Cincinnati, USA) pela leitura crítica feita a este artigo durante sua recente visita ao Brasil. Agradecemos também ao professor Dr. Gilberto Pessanha (Dept ${ }^{\circ}$ de Cartografia-UFF), por ter gentilmente cedido a imagem do satélite IKONOS. Agradecimento muito especial ao Dr. Dieter Muehe (UFRJ) pelo acesso aos dados originais da década de 70 do projeto Geocost. 


\section{Referências}

Bastos A.C. \& Silva C.G. 1995. Study of morphological variations from beach profiles in Piratininga Beach, Niterói -RJ-Brazil. In: Congresso ABEQUA, 5/ Symposium on Coastal Sedimentology, 11, Niteroi, Anais, p. 205-210.

Diretoria de Hidrografia e Navegação (DHN). Tábuas de Marés para o Porto do Rio de Janeiro. Disponível em: http://www.mar.mil.br/dhn/dhn/index.html. Acessado em 31 de janeiro de 2006.

Emery K.O. 1961. A Simple Method of Measuring Beach Profiles. Limnology and Oceanographic, 6:90-93.

Muehe D.C.E.H. 1975. Análise Ambiental no Sistema Costeiro Sul-oriental do Estado do Rio de Janeiro. Dissertação de Mestrado. Pós Graduação em Geografia da Universidade Federal do Rio de Janeiro, p. 141.

Peittijohn F.J. 1975. Sedimentary Rocks. Third Edition. Harper and Row Publishers, $628 \mathrm{p}$.

Salvador M.V.S. \& Silva M.A.M. 2002. Morphology and Sedimentology of the Itaipú Embayment - Niterói / RJ. Anais da Academia Brasileira de Ciências, 74(1):127134.

Santos C.L. 2001. Dinâmica Sazonal e os Efeitos das Ressacas nas Praias de Niterói (Rio de Janeiro). Dissertação de Mestrado. Programa de Pós Graduação em Geologia e Geofísica Marinha da Universidade Federal Fluminense, p.151.
Santos C.L., Silva M.A.M., Salvador M.V.S. 2004. Dinâmica Sazonal e os Efeitos das Ressacas nas Praias de Niterói/ RJ. Revista Brasileira de Geociências, 34(3):355-360.

Silva M.A.M., Resende M.C.C.M., Santos C.L. 1999. Um Estudo sobre a Dinâmica das Praias de Niterói (Baía de Guanabara, RJ). Anais da Academia Brasileira de Ciências, 71(4):962-967.

Silva A.L.C. 2006. Comportamento Morfológico e Sedimentológico do Litoral de Itaipuaçú (Maricá) e Piratininga (Niterói), RJ, nas últimas três décadas. Dissertação de Mestrado, Programa de Pós Graduação em Geologia e Geofísica Marinha da Universidade Federal Fluminense, p.153.

Silva A.L.C., Silva M.A.M., Santos C.L. 2006. Comportamento Morfodinâmico das Praias de Itaipuaçú (Maricá) e Piratininga (Niterói), RJ, nas últimas três décadas. In: Congresso Brasileiro de Geologia, Aracajú, SE, Anais, p. 205.

Souza C.R.G., Filho P.W.M.S., Esteves L.S., Vital H., Dillenburg S.R., Patchineelam S.M., Addad J.E. 2005. Praias arenosas e erosão costeira. In: Souza C.R.G., Suguio K., Oliveira A.M.S., Oliveira P.E. (eds.) Quaternário do Brasil. Ed. Holos, Brasil, p. 130-152.

Manuscrito ID 13472

Submetido em 16 de fevereiro de 2009 Aceito em 26 de novembro de 2009 